Revista de Derecho YACHAQ

ISSN: 1817-597x (impresa) / ISSN: 2707-1197 (en linea)

Centro de Investigación de los Estudiantes de Derecho (CIED)

Universidad Nacional de San Antonio Abad del Cusco

N. ${ }^{\circ} 10-2019$

[pp. 175-194]

Fecha de recepción: 09/08/19

Fecha de aceptación: 16/09/19

\title{
Activación estratégica del derecho en la implementación de políticas mineras
}

\author{
Strategic activation of the law in the \\ mining policies implementation
}

\author{
Vladimir Condo Salas ${ }^{[*]}$
}

\begin{abstract}
: let us assume you have a right, but you ignore that you have it or you are aware of it and you realize that is inconvenient; you will certainly choose not to use it. Let us suppose that you gain benefits by fulfilling the law literally or by applying it in a different sense from what it was intended for: you will probably seek this advantage. Furthermore, if you can bypass an inconvenient law without breaking it so that your current situation improves; you will probably bypass it.

The actors during the implementation of a public policy take these types of decisions time and again. Usually, they deploy the law against each other seeking specifics goals; this is known as a game of actors. Furthermore, if the actors select their decisions among many alternatives, plan their implementation and seek the reaction of the rival, we facing a strategic game of actors.

In this paper, we develop and explain the game of actors and the strategic activation of the law. This paper is based on the analysis of mining public policy and on the study of four cases of implementation of large mining projects; Cañariaco, Tia Maria, Tintaya and Antapacay.

Resumen: supongamos que tiene un derecho, pero ignora que lo tiene o conociéndolo sabe que su ejercicio le es inconveniente; probablemente, no lo activará. Supongamos que obtiene beneficios adicionales al cumplir literalmente la ley o al aplicarla en un sentido diferente para el que fue previsto; probablemente, buscarás este beneficio. Además, si puede eludir una inconveniente ley sin violarla para que su situación actual mejore; probablemente, la eludirá.
\end{abstract}

[*] Doctor en Administración Pública por la Escuela de Administración Pública de Suiza (Swiss Graduated School of Public Administration - IDHEAP), Máster en Medioambiente Dimensiones Humanas y Socio-económica y Máster en Derecho Ambiental por la Universidad Complutense de Madrid (UCM), abogado por la Universidad San Antonio Abad del Cusco (UNSAAC). Investigador y consultor en temas de implementación, análisis y evaluación de políticas públicas. Correo: vladimircondo@gmail.com 
Los actores, durante la implementación de una política pública, toman este tipo de decisiones una y otra vez. Despliegan sus recursos y la ley, unos contra otros, buscando objetivos específicos; esto se conoce como juego de actores o juego de rivales. Además, si los actores seleccionan sus decisiones, entre muchas alternativas, planifican su implementación y buscan deliberadamente la reacción del rival, nos encontramos ante un juego estratégico.

En este artículo, desarrollamos y explicamos el juego de actores y la activación estratégica del derecho. Este trabajo se basa en el análisis de la política pública minera y se desarrolla sobre la implementación de cuatro proyectos mineros (Cañariaco, Tía María, Tintaya y Antapacay).

KEYWORDS: activación estratégica, derecho, políticas públicas, minería, triángulo de actores, juego de actores.

\section{INTRODUCCIÓN}

Una de las fases cruciales de las políticas públicas es su implementación, entorno a esta gira todo el ciclo de una determinada política públi$\mathrm{ca}^{[1]}$. Esta fase implica el conjunto de procesos que buscan la realización concreta de los objetivos planteados (Knoepfel, P. et al., 2006 y 2011) y que en una fase posterior serán evaluados. En estos procesos, la activación del derecho por los actores juega un rol determinante para el éxito o el fracaso de la politica pública ${ }^{[2]}$.

Diversas investigaciones realizadas con el marco de análisis del Institutional Resouces Regime (en adelante «IRR»), en diferentes contextos y sistemas políticos estudiaron la compleja implementación de las políticas públicas (Knoepfel, P. et al., 2006 y 2017; Schweizer, R., 20014; De Buren, G. 2014 y 2015; Condo, V., 2017). Se lograron identificar patrones de constelación de actores, denominada triángulo de actores, sus rivalidades y recursos. También, se logró identificar patrones de juego de actores, por el cual la activación de los recursos de acción pública sigue finas estrategias de anticipación de eventos.

El juego estratégico comienza cuando los actores de la constelación, cuyos valores y/o intereses sean individuales o colectivos, difieren y rivalizan unas con otras. Los rivales despliegan un intenso juego estratégico para influenciar en la implementación de la política pública (en adelante «la política»). Así, la autoridad político-administrativa pierde el monopolio de la implementación de la política, bajo una lógica Top-Down, y otros actores intervienen, con mayor o menor poder, para influenciar su decisión, bajo una lógica Botom-Up. En el caso de la política minera, hemos observado que por este juego se va modificando y adaptando a los intereses y/o valores de los actores (Condo, V., 2017).

Entonces, la implementación de una política implica necesariamente un contexto indisociable de lucha de poderes y de interacciones entre los actores implicados. Estos, con frecuencia activan el derecho para la configuración o reconfiguración de la política y sus objetivos, así adaptarlas a sus intereses. Por el juego de rivales, el derecho (subjetivo y objetivo) como un recurso de acción pública, juega un rol crucial en la implementación de la política.

Los actores mediante complejas estrategias de activación del derecho rivalizan para imponer sus intereses y/o valores frente a los demás. Para ello, los rivales buscan legitimar su posición, temporalmente y en un determinado territorio, a través de una decisión vinculante. Resulta por ello, que en el campo del análisis de las políticas públicas, al derecho se

[1] Aclaramos que esta fase no es más ni menos importante que las otras fases del ciclo de una política pública. Sin embargo, esta fase juega un rol central desde la puesta en la agenda pública, pasando por la programación de ella y su evaluación.

[2] Tómese en cuenta que el derecho no solo es importante en esta etapa, sino a lo largo del ciclo de una política pública. Por ende, por el derecho se puede identificar un problema público, puede esta ponerla en la agenda pública, generalmente, mediante el derecho se formula y se adopta el programa político, esta también regula su implementación y su evaluación. 
le reconoce como la fuente de legitimación por excelencia de toda acción pública (Knoepfel, P., 2017).

En el presente artículo desarrollamos los patrones de la activación estratégica del derecho que los actores despliegan durante la implementación de la política pública minera. Estos patrones inicialmente fueron identificados por varios estudios de casos realizados por el grupo de investigación del departamento de políticas públicas y sostenibilidad de la escuela de Administración Publica de Suiza (IDHEAP).

Estructuramos el presente trabajo en seis aspectos: 1) la configuración de los actores implicados y las hipótesis de análisis de políticas públicas, 2) los actores y sus recursos de acción pública. 3) el comportamiento estratégico, 4) el derecho como recurso de acción pública, 5) derechos susceptibles de ser activados, y 6) las estrategias de activación del derecho. Al final, presentaremos, a modo de conclusiones, la utilidad de la identificación de estos patrones y sus posibles usos.

Este trabajo es una síntesis de uno de los aspectos investigados en nuestra tesis doctoral presentada para obtener el grado de Doctor en Administración Pública ${ }^{[3]}$. Nuestro trabajo de investigación se avocó al estudio de la política pública minera y se desarrolla sobre estudios de casos de implementación de proyectos mineros como Tintaya, Antapacay, Kañariaco y Tía María. Para el presente trabajo, presentaremos únicamente los patrones de estrategias de activación del derecho identificadas en los casos estudiados.

\section{ELEMENTOS PARA ENTENDER LA ACTIVA- CIÓN ESTRATÉGICA}

La activación del derecho depende, fundamentalmente, de los intereses y valores de los actores y de los recursos de acción pública que poseen (en adelante «recurso»). El actor puede estar revestido de poder público y activar el marco legal de sus competencias, es el caso de las autoridades públicas de todos los niveles de gobierno. El actor puede ser uno privado, quien conforme a sus intereses activará el marco legal que le corresponda, ya sea del derecho público o privado o ambos, es el caso de los administrados.

Se puede dar el caso de que un actor no esté directamente implicado o formalmente reconocido por la política pública, pero despliega estrategias para introducirse en los procesos de implementación. Así, buscará velar por sus intereses y/o valores, es el caso de muchas organizaciones sociales y organismos no gubernamentales.

Por lo mencionado, se hace irrefutable que la identificación de la configuración de los actores, de su posicionamiento dentro de la implementación de una política y de sus recursos, tiene una importancia fundamental. Por ello, una correcta identificación de estos es importante para una correcta identificación de sus estrategias y motivaciones.

\subsection{La configuración de los actores y las hipó- tesis de análisis}

El marco de análisis propuesto por el IRR consiste en identificar tres tipos de actores de la política pública a analizar: los actores públicos, también llamados autoridad política-administrativa, los grupos objetivos y los beneficiaros. Estos tres actores, llamados también «el triángulo de actores», constituyen el patrón fundamental para el análisis de una política pública.

Al triángulo de actores se tiene que agregar los actores terceros, quienes son afectados positiva o negativamente, directa o indirectamente, con la implementación de la política pública) (Knoepfel, $\mathrm{P}$. et al., 2006). Para ello, se tiene que hacer un análisis más minucioso de la implementación de la política pública a estudiar.

La identificación de los actores y su configuración es un proceso empírico por excelencia. En razón a esto, hemos identificado, en un primer momento, una configuración básica sobre la revisión bibliográ-

[3] Para mayor detalle véase mi tesis doctoral publicada en el sitio oficial de la Universidad de Lausana o en el siguiente link: https://serval.unil.ch/en/notice/serval:BIB_75FC1D6F26FB

El Dr. Peter Knoepfel fue el director de esta tesis, quien con aguda y pertinente lectura dirigió y corrigió este trabajo de investigación. 
fica y el diseño de la política minera peruana (ver esquema $\mathrm{N}^{\circ}{ }^{1}$ ). En un segundo momento, hemos identificado una configuración más completa y más compleja, resultado de la lectura fina y detallada de los casos estudiados.

Para el presente trabajo, nosotros expondremos la configuración de base ${ }^{[4]}$ y en base a ella, más adelante, identificaremos los patrones del comportamiento estratégico.

\section{a. La autoridad político-administrativa}

Este actor es la autoridad administrativa, es el competente para la implementación de la política pública. Su competencia nace, casi siempre, de un mandato legal. Además, está dotada de un conjunto de recursos de acción pública tales como recurso económico, personal, infraestructura, fuerza y del mismo derecho como recurso y otras.

La autoridad político-administrativa generalmente está estructurada en jerarquías administrativas (vertical) y tiene permanente interacción con otras autoridades político-administrativas y/o actores (horizontal). Los actos administrativos son el principal medio por el que este actor impulsa la implementación de la política (Aguado, M., 2009 y Castro, X., 2009). Puede también impulsarla mediante actos distintos como por ejemplo, contratos privados (Condo, V., 2007). En todos estos actos, el derecho es el fundamental recurso activado, por el principio de legalidad.

Este actor, también, despliega estrategias de activación de los recursos que posee, al igual que los otros actores. Aclaramos que todo acto de implementación de esta autoridad puede ser objeto de revisión por la misma autoridad u otra superior, incluso, en otro fuero, tal como el judicial.
La autoridad político-administrativa de la política minera es el ministerio de Energía y Minas ${ }^{[5]}$ (MINEM), la competente para la implementación de la política pública minera, en particular para la implementación de proyectos mineros a gran escala. El marco normativo con el que el MINEM implementa la política es numerosa y compleja (ver esquema N. 2).

\section{b. El grupo objetivo}

El grupo objetivo es el actor o conjunto de actores cuyo comportamiento es considerado, por la política pública, como la causa directa o indirecta del problema colectivo que se busca solucionar (Knoepfel, P. y otros, 2006 y 2011). Este actor puede ser una persona física o jurídica, puede estar integrada por un único actor o por varios. Estos pueden causar el problema de manera conjunta o individualmente.

Este actor, o actores, es por un lado el objeto de intervención de la política pública, se busca que su comportamiento cese o se modifique. Para tal efecto, se despliega distintas modalidades de intervención, que pueden ir desde la intervención directa, hasta los incentivos indirectos. Por otro lado, este actor es detentor, o puede serlo, de derechos y/u obligaciones que le son otorgadas e/o impuestas por la misma política pública y que pueden ser activadas conforme a sus intereses.

Para la política minera, este actor está identificado como la relación de dos grupos de actores; por un lado, el promotor minero y, por el otro, el propietario y/o usuario de bienes y servicios. Esta identificación responde a la relación estrecha que ambos mantienen en el marco de la implementación de la política minera ${ }^{[6]}$. Pero sobretodo resaltamos su

[4] La identificación y configuración completa y compleja de los actores de la política minera no son presentados en este trabajo; sin embargo, ella se encuentra en nuestra tesis doctoral minuciosamente descrita y esquematizada.

[5] El MINEM como tal fue creada por decreto ley $N .^{\circ} 17271$ del 3 de diciembre de 1968. Desde entonces, fue objeto de innumerables modificaciones tanto de sus competencias como de su estructura. Antes de la creación del MINEM la política minera estaba dirigida por el ministerio de obra pública y de planificación.

[6] Ambos actores detentan derechos reales, uno la concesión otorgadas en el subsuelo y el otro detenta los derechos de propiedad $\mathrm{y} / \mathrm{o}$ de uso en la superficie. 
relación de rivalidad (ONDS 2013, DP 2007, 2012), los intereses $y / 0$ valores de uno se oponen, aparentemente, a los intereses y/o valores de los otros. Así, por ejemplo, el agro no es compatible con la minería, ni con los usos del agua (Bebbington, A. et al., 2009), o que el desarrollo no es posible sin la minera (Benavides, R., 2012), etc.

La rivalidad existente, real o potencial, entre estos actores, trae como consecuencia que la política pública minera no se implemente como se ha diseñado y, por ende, no cumpla con sus objetivos. Esta rivalidad, que se puede observar en cada uno de los procesos de implementación de proyectos mineros, desde nuestro punto de vista genera efectos negativos para los beneficiarios de la política pública.

\section{El promotor minero}

Este actor es el concesionario, la sociedad minera y/o el inversor minero. Es el que detenta los derechos de exploración y/o explotación de la concesión minera en el subsuelo. Este actor, puede tener complejas estructuras internas, todas de acuerdo al derecho civil y comercial; sin embargo, para la política minera es el promotor minero.

Este actor, por la concesión que posee, detenta un conjunto de derechos y obligaciones, activables $\mathrm{y} / \mathrm{o}$ susceptibles de ser movilizados, por el derecho público o privado ${ }^{[7]}$. Entre otros, este actor tiene derecho de explorar y explotar su concesión. Para hacerla efectivo su derecho, solicita al MINEM diversas licencias mineras, de esta forma activa el derecho.

El promotor minero, al activar la concesión, se introduce al juego de actores en relación directa e intensa con los actores que poseen derechos de propiedad o de uso en la superficie. La totalidad o parte de estas relaciones se grafican en los estudios de impacto ambiental (en adelante EIA) y los procedimientos para otorgar licencias mineras.
Por ejemplo, la exploración u explotación no puede desarrollarse sin el previo consentimiento del propietario del suelo.

\section{El detentor de derechos}

Es el actor propietario del suelo o el detentor de derechos de uso, por ejemplo, del agua, y por debajo del cual se encuentra la concesión minera. Es importante subrayar que estos actores no detentan ningún derecho sobre el subsuelo. El principio de accesión, en lo que concierne a la propiedad del suelo, no se aplica al subsuelo ni a los recursos que se encuentran en ella.

Estos actores no pueden oponerse a la concesión minera, porque no están habilitados para ello. Además, la política minera impone a estos actores límites a sus derechos. Por ejemplo, el propietario no puede oponerse a la solicitud de la servidumbre y/o la expropiación forzosa si no únicamente en lo que respecta a la compensación.

En la mayoría de los casos, este actor entre al juego de actores activando derechos que le otorga otras políticas públicas, por ejemplo, que refuerzan su propiedad, y evitan activar los reconocidos por la política minera. Es muy frecuente que se activen derechos otorgados en las políticas ambientales, agrícolas, de protección de comunidades campesinas y/o de pueblos indígenas, las de protección de derechos humanos y muchas otras conforme a sus intereses.

En los casos estudiados, identificamos que estos actores tienen derechos de propiedad y de uso, más o menos definidos. Los títulos de propiedad les otorgan una posición estratégica en el juego de actores, al punto de que si son estratégicamente activados son decisivos para el éxito o fracaso de la política minera (Condo, V., 2017). En el caso de los títulos de uso, la posición de los actores es más débil; sin embargo, con el auxilio de otras políticas y estrategias finamente elaboradas estas adquieren un valor fundamental.

[7] Dado que la concesión minera es un derecho real, los elementos del derecho de propiedad, por ejemplo, pueden ser movilizados por el promotor minero con el objetivo de explotar efectivamente la concesión. El derecho de uso, de disfrute y de disposición son con frecuencia movilizados para ejecutar un proyecto minero. En otro, EI TUO de la LGM en su título XIII aborda, por ejemplo, los contratos mineros, por esta se moviliza otros derechos. 


\section{c. Los beneficiarios finales}

Los beneficiarios de una política pública son los que en principio sufren del problema que genera el grupo objetivo con su comportamiento. Estos actores pueden ser personas físicas o jurídicas que esperan que la implementación de la política sea exitosa, porque ellos obtienen beneficios, más o menos directos, de ese éxito.

Generalmente estos actores, cuando entran al juego de actores, coadyuvan a la implementación de la política y pueden entrar en coalición con la autoridad político-administrativa. Sin embargo, no siempre es el caso, muchas veces estos tienen intereses y/o valores distintos al de la autoridad o no están bien identificados y movilizarlos puede ser complicado por falta de recursos.

Para la política minera tres son los actores beneficiarios. Estos son las autoridades de los tres niveles de gobierno (local, regional y nacional). Resaltamos que la autoridad local es la mayor beneficiaria. Es beneficiaria por que recibe, o podrían recibir, canon minero una vez que un proyecto entra en fase de explotación en su jurisdicción, en algunos casos excepcionales antes a esta fase ${ }^{[8]}$ (IIMP-MINEM, 2010; MINEM, 2014 y 2015).

Sin embargo, los gobiernos locales no siempre favorecen la implementación de la política. Al contrario, con frecuencia entran en coalición con los propietarios y/o detentores de derechos de uso para oponerse a la implementación. En esta lógica, este actor entra al juego de actores y usa estratégicamente sus competencias para oponerse a la política minera.

\section{d. Los terceros}

Los terceros son el grupo de actores que están compuestos por aquellos que se benefician indirectamente (terceros ganadores) o se perjudican indirectamente (terceros perdedores) con la implementación de la política. Este grupo está compuesto, generalmente, por los habitantes locales y/o asociaciones sociales que no integran ninguno de los actores antes mencionados.

Por ejemplo, los terceros ganadores con la implementación de un proyecto minero serían los que comercian con bienes y servicios. Los terceros perdedores serían los habitantes locales que no integran el grupo objetivo ni el grupo de terceros beneficiarios. Estos actores no están identificados o son vagamente identificados en los EIA y, generalmente, aparecen durante la implementación de un proyecto minero en coalición con los actores.

Hasta aquí hemos mostrado un patrón básico de la configuración de los actores de la política pública en general y de la política minera en particular. Sin embargo, aclaramos que la configuración de los actores durante la implementación de la política deviene más compleja y se satura de diversos actores.

Para el presente trabajo, ponemos en consideración una configuración de actores, básica, pero suficiente para desarrollar los patrones de estrategias para la activación del derecho. En nuestra tesis doctoral, cuyo objetivo fue más amplio, se puede encontrar una visión de la configuración de actores completa y compleja, tal como se presenta en el mundo real ${ }^{[9]}$.

Para graficar esta configuración, presentamos a continuación nuestro esquema de configuración del triángulo de los actores a la cual agregamos los actores que intervienen en la implementación de la política pública minera (ver esquema N. 1). Así, en esta parte resaltamos los actores dentro de la constelación y sus relaciones y las hipótesis teóricas para el análisis de políticas públicas adaptadas para el análisis de la política minera.

[8] El canon minero es una partida presupuestal en favor de los gobiernos locales y que es directamente derivada de los impuestos recaudados de la actividad minera. Así, la implementación de un proyecto minero favorece económicamente a estas autoridades y les permite asegurar los servicios básicos que son de su competencia, por ejemplo, el agua potable, la electrificación, infraestructura para educación y otros, así como para toda competencia inscrita dentro de sus leyes orgánicas.

[9] Es menester aclarar qué es el juego de actores y sus estrategias para movilizar y activar recursos, según las reglas de juego de la implementación de la política que incitan la aparición de esta configuración. 


\subsection{Hipótesis de análisis}

Las hipótesis con las que trabaja el IRR están orientadas a la identificación de los actores y de posicionarlas unos en relación a otros, en un triángulo. Se identifica su relación bajo un modelo de causalidad $^{[10]}$, para ello se estructuran las siguientes tres etapas:

Primero, se tiene que definir el problema público a resolver, es decir, la insatisfacción social destinada a ser resuelta una vez implementada la política pública. Segundo, se tiene que identificar la relación de causalidad, o la hipótesis de causalidad ${ }^{[11]}$, es decir, saber quién o qué y cómo provoca el problema público a resolver. Tercero, se determina la lógica de intervención o formular la hipótesis de intervención, es decir, qué hacer y/o cómo intervenir para resolver el problema público identificado (Knoepfel, P. et al., 2006: 45-67). Para el análisis de políticas públicas mineras, nosotros hemos identificado estas premisas como sigue:

Aclaramos que las premisas e hipótesis que presentamos aquí no son hipótesis de investigación, sino de análisis ${ }^{[12]}$. Nos permite identificar los actores y sus intereses y/o valores, así como su interrelación en el juego estratégico durante la implementación de la política.

\section{Definición del problema público}

La ausencia de explotación de recursos mineros (a gran escala) puede conllevar a un riesgo de insuficiencia de recursos económicos necesarios para el aprovisionamiento de recursos públicos esenciales.

Uno de los fines de la política minera es la recaudación de recursos económicos a través de la explotación de minerales (MINME, 2014 y 2015). Entonces, la paralización o ausencia de proyectos mineros provocaría un problema, real o potencial, de insuficiencia, en mayor o menor medida, de recursos para los estamentos de gobierno, nacional, regional y sobretodo local.

\section{Hipótesis de causalidad}

Si las autoridades político-administrativas quieren asegurar una captación suficiente de recursos económicos para asegurar los servicios públicos esenciales a través de la explotación de recursos mineros (a gran escala), ellos deben incitar a los detentores de derechos de concesión, de propiedad o de uso a que faciliten la implementación de grandes proyectos mineros bajo ciertas condiciones.

En los casos estudiados, observamos que las rivalidades entre el promotor minero con los propietarios $\mathrm{y} / \mathrm{o}$ detentores de derechos de uso

[10] La construcción de nuestra constelación de actores, para la política minera, sigue esta modalidad y cuyas hipótesis son las siguientes: identificación del problema público a resolver, la hipótesis de causalidad y la de intervención.

[11] La hipótesis causal de este triángulo busca identificar quién o qué es el responsable del problema colectivo a resolver (grupo objetivo) y de quién se espera el cambio de comportamiento cuando se implemente la política pública. Esta última es el vínculo entre este grupo y los beneficiarios. La hipótesis de intervención tiene como objetivo establecer la modalidad de resolución del problema colectivo a través de una política pública. Esta modalidad implica que la autoridad político-administrativa asegure la captación de recursos suficientes a través de la explotación a gran escala de los recursos mineros, ello para asegurar los servicios básicos. Para tal fin, se debe incitar a los concesionarios y a los propietarios del suelo a permitir y/o facilitar la implementación de grandes proyectos mineros bajo ciertas condiciones.

[12] Todas las políticas públicas están programadas bajo estas hipótesis o premisas, por ello, es un patrón de análisis. Sin embargo, en muchos casos no suelen ser expresas, ni precisas, sino tácitas y ambiguas, ni suelen estar contenidas en un único texto, muchas veces se tiene que hacer una revisión exhaustiva de todo un conjunto de documentos, legales y técnicos para identificarlas. 
no permite, que se explote, los recursos mineros. Aparentemente, sus intereses y/o valores están contrapuestos y no pueden coexistir (ONDS, 2013; DP, 2007 y 2012). Sin embargo, también hemos estudiado casos donde estos se ponen de acuerdo para permitir la implementación de proyectos, sin renunciar a sus intereses $\mathrm{y} / \mathrm{o}$ valores.

\section{Hipótesis de intervención}

Si las autoridades político-administrativas quieren asegurar una captación suficiente de recursos económicos a través de la explotación a gran escala de los recursos mineros, ellos deben incitar, en su caso, facilitar la constitución de un acuerdo regulativo local que lleve a la explotación efectiva de los recursos bajo ciertas condiciones.

La lógica de intervención de la autoridad político-administrativa para que los actores rivales, grupo objetivo, puedan cambiar su conducta varía de proyecto en proyecto. Planteamos que se debiera incentivar la constitución de un acuerdo regulativo entre las partes que incluya, en la mayor cantidad posible, sus intereses y valores. Los EIAs deben ser uno de estos acuerdos.

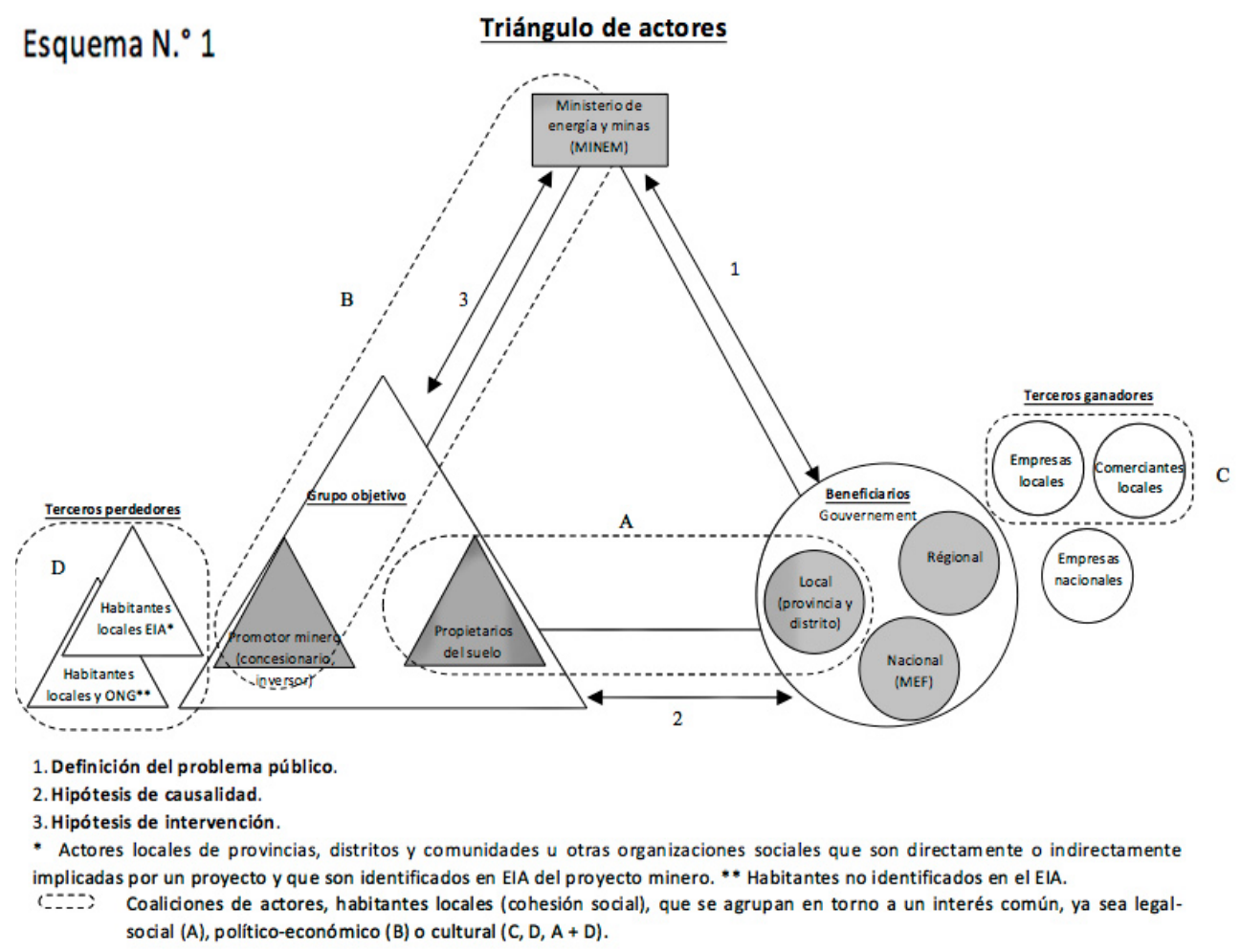

Fuente: ilustración propia adaptada de Knoepfel P., 2006, p. 63.

\subsection{Los actores y sus recursos de acción pública}

La implementación de una política en un contexto democrático está llena de oportunidades, donde los actores dotados de recursos, se interrelacionan, intercambian y se confrontan. Es un espacio de lucha de poderes en defensa de intereses y/o va- lores, donde los recursos de acción permiten a los actores intervenir en la producción de decisiones.

La configuración de los actores que presentamos es también el resultado de la interacción y confrontación de los actores implicados en la política minera. Esta configuración refleja sus rivalidades y 
coaliciones, así como también el juego estratégico desplegado para legitimar sus intereses y/o valores. En suma, el triángulo de actores refleja el juego estratégico de poderes.

Por ejemplo, el promotor minero puede solicitar, conforme a su derecho, licencias de exploración o la concesión de beneficio, la servidumbre o la expropiación forzosa. Por su parte, el propietario puede denegar el acceso a su propiedad u oponerse a la expropiación. La autoridad puede o no otorgar las solicitudes y sus decisiones pueden ser apeladas.

Cuando el juego se intensifica, se acude a estrategias que van al límite de las normas. Los detentores de derechos, los terceros y las autoridades locales forman una coalición y cuestionan, formal e informalmente, la implementación de la política. Por su parte, el promotor minero y la autoridad política-administrativa también forman coalición y despliegan estrategias políticas, legales y económicas para contrarrestar el juego de sus oponentes.

El Institutional Ressources Regime (IRR) se interesa en este juego de actores, porque él determina y/o influencia los resultados, intermediarios o finales, de la implementación de la política pública (Knoepfel, P. et al., 2006; Knoepfel, P., 2017). Para entender este juego de poderes se ha identificado un catálogo de 10 recursos con los que cuentan los actores y susceptibles de ser movilizados estratégicamente ${ }^{[13]}$.

Este catálogo ha mostrado pertinencia para el análisis del comportamiento de actores en muchas investigaciones (Knoepfel, P. et al., 2006; De Buren,
G., 2014; Schweizer, R., 2014; Knoepfel, P., 2017). Por ello, traemos a luz la movilización y activación estratégica del recurso derecho y, particularmente, del derecho de propiedad y de los derechos de uso en la política minera.

\section{LA ACTIVACIÓN ESTRATÉGICA DEL DE- RECHO}

El juego de actores es literalmente un juego de actores racionales que están atribuidos de capacidad de acción y de reacción. Estos se posicionan unos en relación a los otros conforme a sus intereses y/o valores, así entran en una relación de poder; de intercambio, de negociación, de acuerdos, pero sobretodo de imposición.

Los actores normalmente intervienen en el juego con el objetivo de ganar, ello es implícito a todo juego estratégico, para así imponer su posición frente a los otros. Para ello, cada uno de los recursos que poseen, en mayor o menor cantidad, son los elementos de poder a disposición y cuya activación y/o movilización provoca, o anticipa, la modificación de la política pública.

EI IRR asumen que el juego de actores no es ilimitado[14], por el contrario, está enmarcado por normas (el derecho) (Knoepfel, P. et al., 2011; Schweizer, R., 2014). Estas normas canalizan el comportamiento del actor, modelan el objetivo de su estrategia, orientan sus alternativas, pero sobre todo busca equilibrar los efectos de este juego. También, prohíben ciertos comportamientos y desincentiva de otros.

[13] Este catálogo está compuesto por los siguientes recursos: 1) Recurso Consenso, o legitimación secundaria, es el apoyo de uno o varios actores de la política pública a otro actor; 2) Recurso Patrimonio son todos los bienes materiales a disposición de los actores (por ejemplo, sus locales, vehículos motorizados, etc.); 3) Recurso Fuerza es la capacidad de obtener un resultado con el uso de la fuerza física, su uso implica llevar al extremo la aplicación de normas sin llegar a transgredirlas; 4) Recurso Personal, o recurso humano; 5) Recurso Económico, dinero del que disponen los actores; 6) Recurso Información es el recurso conocimiento, implica tanto la posesión como su producción; 7) Recurso Organización es la estructura interna de los actores; 8) Recurso Sustento Político es la primera fuente de legitimación, creada por decisión política (inscrita en la ley o no); 9) Recurso Tiempo, el control del tiempo y plazos para el juego estratégico; 10) Recurso Derecho, se detallará en el presente trabajo.

[14] El IRR recoge postulados del neoinstitucionalismo para el análisis de políticas públicas de las instituciones y de los actores. De esta se desprende que los actores rigen su comportamiento en el marco de reglas de juego. 
Por el juego estratégico se busca obtener decisiones que legitimen intereses y/o valores y que tengan, idealmente, fuerza vinculante. Estas pueden tomar la forma de un contrato, una decisión administrativa, una sentencia judicial, hasta de una ley. La forma que adopte tiene que ser susceptible de ser activada para asegurar su legitimidad y, así, imponerla al conjunto de actores.

Para entender la activación estratégica del derecho, a continuación, explicaremos qué normas y cómo son estratégicamente activadas. El contexto del análisis es la implementación de la política minera a trevés de grandes proyectos mineros (Tintaya, Antapacay, Cañariaco y Tía María). Explicaremos algunas estrategias identificadas sin abordar en detalle los casos.

\subsection{El comportamiento estratégico de los actores}

Del análisis del comportamiento de los actores del triángulo, en la fase de implementación de la política minera, observamos que activan el derecho sistemáticamente. Además, adaptan su comportamiento a las estrategias de sus rivales y las que ellos mismos diseñan y que su actuación no es aislada o casual, sino que es un comportamiento racional[ ${ }^{[15]}$.

En esta línea, Remi Schweizer identifica que el comportamiento estratégico es intencional, selectivo, dinámico, relacional, y contextual (Schweizer, R., 2014). Para el presente trabajo nos atrevemos a profundizarlo basado en nuestra tesis doctoral. Así, podemos indicar que un comportamiento estratégico es también aprendido (Condo, V., 2017).

\section{a. Comportamiento intencional}

Es intencional, porque busca alcanzar un objetivo más o menos explícito, más o menos limitado, más o menos coherente. No busca necesariamente la maximización de un interés económico y/o material, a veces se busca satisfacer ideales, tales como la justicia o la igualdad. En los casos es- tudiados, los actores desean o avizoran un objetivo previamente identificado.

La autoridad político-administrativa busca, por ejemplo, incrementar la recaudación fiscal (MINEM, 2014 y 2015) para financiar los servicios públicos de base. El promotor minero busca, esencialmente, el beneficio económico. Los detentores de derechos de propiedad y/o usos buscan proteger los beneficios que les ofrece tal condición o maximizarlos, en algunos casos, se involucran en la protección de su forma de vida tales como el medioambiente y su cultura.

\section{b. Comportamiento selectivo}

Implica una elección entre varias opciones según las normas del juego, según su realización y la oportunidad que se presente. Por ejemplo, los actores están dotados de una serie de derechos potencialmente activables, de ellos se puede activar uno, algunos o todos, o simplemente reusarse a activarlos. Además, se tiene la oportunidad de activarlos en un determinado tiempo.

Por ejemplo, los detentores de derechos de propiedad y/o uso activan normas que mejor protegen sus intereses y/o valores, mas no las normas de la política minera. Así, en algunos casos se activan normas de políticas de protección de derechos de pueblos indígenas, porque esta protege mejor la propiedad que el de comunidades campesinas y, esta a su vez, mejor que la propiedad individual y que la propiedad pública. En esta misma lógica, el promotor minero busca activar normas que favorezcan el proyecto minero, como veremos más adelante.

\section{c. Comportamiento dinámico}

El comportamiento estratégico se adapta a un contexto temporal y responde a una lógica de anticipación y de reacción. Implica un plan diseñado con anticipación, a corto o mediano plazo, se implementa, se adapta y se rediseña constantemente conforme a los acontecimientos. Además, conside-

[15] Aclaramos que un comportamiento racional no implica necesariamente el dominio de la información ni el control de todas las variables fácticas, o la ausencia de ambigüedades o de elementos subjetivos tales como las creencias y los valores. 
ra un margen de maniobra y de error, porque no es posible prever todos los escenarios, ni obtener el objetivo buscado en las condiciones deseadas.

Para la implementación de proyectos mineros, los promotores invierten muchos recursos; para la obtención de la concesión, licencias, elaboración de EIA y entre otras. Sin embargo, no siempre se llega a la fase de explotación y se tienen que corregir y reiniciar el proceso. Los actores detentores de derechos con frecuencia también modifican su estrategia y la dinamizan constantemente para responder al contexto sin renunciar a sus objetivos.

\section{d. Comportamiento relacional}

El comportamiento estratégico se ubica en un contexto de relación entre actores rivales, basado en la acción, reacción y la anticipación de eventos. Por ello, se considera permanentemente la interacción de las estrategias, reales o posibles, de los otros actores. Así, una acción de un actor implica, o se espera que genere, la reacción del otro de la forma que se haya previsto.

Se observa con frecuencia que la presentación de un EIA, para exploración o explotación, provoca la inmediata reacción de los detentores de derechos de propiedad y de usos de agua. La decisión de la autoridad-administrativa, en favor o en contra, generalmente, es apelada ante las instancias superiores, existen casos que han involucrado instancias internacionales.

\section{e. Comportamiento contextual}

Se inscribe en un marco de oportunidades y limitaciones que son definidas por las instituciones, por las normas y, específicamente, por el procedimiento administrativo. Este contexto puede ser muy amplio; sin embargo, nos interesa estudiar en casos concretos la activación estratégica del derecho en los procedimientos de entrega de licencias mineras.

Por ejemplo, el contexto de un estado de derecho es fundamental para el juego estratégico; en un contexto dictatorial, el juego no sería posible o se vería muy reducida. El contexto próximo a los actores también lo es, así un propietario y/o usuario dentro de una estructura social cohesionada, como una comunidad campesina o una junta de regantes, es más fuerte que fuera de ella. Un promotor con pasivos ambientales encontrará más resistencia frente al que lo no tenga.

\section{f. Comportamiento aprendido}

A demás, identificamos que las estrategias son reproducidas, permanentemente, durante el proceso de implementación de la política minera. Identificamos que algunas fueron aprendidas de anteriores casos y se replican en los nuevos. Por ello, deducimos que una estrategia es aprendida, adaptada y mejorada (producto de ensayo y error), pero sobre todo transmitida.

La estrategia de activación del derecho, que en realidad es conocimiento empírico y estructurado, es transmitida por diversos medios; de manera oral, por la prensa escrita, por estudios y publicaciones académicas, por decisiones administrativas y hasta por la jurisprudencia. En las entrevistas que realizamos a actores de distintos proyectos, observamos que sin tener formación jurídica tienen conocimiento agudo del derecho que les concierne.

\subsection{El derecho como recurso de acción pública}

La política minera se implementa siguiendo la modalidad de incentivos ${ }^{[16]}$ y bajo una lógica TopDown. Para ello, se activan esencialmente el conjunto de normas de la política minera y se sigue, o se intenta seguir, estrictamente lo previsto en ellas (ver esquema N. ${ }^{\circ}$ 2).

Así, se espera que el promotor minero active su derecho a solicitar la concesión minera, las licencias de exploración y la concesión de beneficio, etc. De los detentores de derechos de propiedad o de uso, a otorgar servidumbres o de transferir la propiedad y sus licencias de uso si lo poseen. Ideal-

[16] Téngase en cuenta que el objetivo de la política pública minera es incrementar la recaudación fiscal para el sustento de las obligaciones del Estado. Con ese propósito la autoridad incentiva a que los proyectos mineros lleguen hasta la fase de explotación. 
mente, se espera que se llegue, conforme a ley, a la fase de explotación.

Sin embargo, los actores no siempre están de acuerdo con la modalidad ni la lógica de la política minera y buscan impedir su implementación o modificarla para adaptarla a sus intereses y/o valores. Para ello, bajo una lógica Bottom-Up activan distintas normas de la misma política minera o de otras, para adaptar la política al mundo real.

Hemos observado que la política minera está dominada por un positivismo exacerbado, muy jerárquico y muy cerrado. Así, su implementación se limita estrictamente a aplicar la norma a los supuestos contemplados (Lógica Top-Down). Se valora demasiado los efectos pragmáticos y utilitaristas a corto plazo, no se valora la solución alternativa o creativa y se limita extremadamente, muchas veces se reprime, el pensamiento crítico (Condo, V., 2017).

Siguiendo la posición de Danièle Lochak, este comportamiento es la materialización de un fetichismo de la norma y de una sacralización del derecho, que por mucho tiempo ha ocultado la realidad detrás de la objetividad de la norma (Lochak, D.,1989 citado por Schweizer, R., 2014).

El IRR atribuye al derecho una función más amplia y más social, lo saca y lo estudia fuera del mundo de los juristas, abogados y jueces. Estudia el derecho desde otra perspectiva, por ejemplo, como un recurso de acción pública (Knowpfel, P., 2017). No adopta las normas únicamente como imperativas absolutas, sino que reconoce su heterogeneidad creciente en los procesos de implementación de políticas públicas (Schweizer, R., 2014).

Esta forma de entender el derecho, en la vida real, fue largamente aplicada. Los actores saben que aplicando las normas mecánicamente no pueden defender o imponer sus intereses y/o valores. Por eso, la dotan de notas de individualidad a través de la activación estratégica, cuando las normas son materializadas, cuando pasan de ser general y abstracta a concreta e individual.
Entonces, el derecho como recurso de acción pública y su activación estratégica rompe con la lógica Top-Down y con el monopolio de la autoridad político-administrativa de aplicación legalista y vertical de las normas en la implementación de una política. Convirtiéndose así, en un instrumento estratégico de construcción, interacción y de intercambio con los actores, aplicado en un contexto político y social y que sigue una lógica de Bottom-Up.

Aclaramos que la activación estrategia del derecho no considera la violación de la norma, en algunos casos se puede jugar con sus límites, pero jamás la transgrede ${ }^{[17]}$. Sin embargo, los actores, sobre todo la autoridad político-administrativa, tienen un margen de apreciación de la norma y de maniobra (De Buren, G., 2014). Es sobre estos que el juego estratégico se desarrolla.

Antes de abordar las estrategias de activación del derecho, describiremos de manera sucinta las normas susceptibles de ser activadas en la política minera.

\subsection{Derechos susceptibles de ser activados}

El triángulo de actores y nuestras hipótesis de análisis de la política minera nos indican qué tipo de normas son las que la regulan. Así, partimos de la idea de que los actores activan derechos otorgados en la política minera (ver esquema $\mathrm{N}^{\circ}{ }^{2}$ ). Sin embargo, no se limitan a ellos y pueden o deben activar otros, tales como la política económica, ambiental, sociales, cultura, etc.

Así, todas las normas jurídicas son susceptibles de ser activadas. Para ello, se toma en cuenta su clasificación según el campo de aplicación (público y privado), su jerarquía (la constitución, leyes, reglamentos y decretos) y su carácter escrito (positivo) u oral (consuetudinario). Asimismo, su contenido para su activación, sea derecho material o formal, derecho subjetivo u objetivo.

Nosotros presentamos aquí dos categorías de derecho unánimemente aceptadas por la doctrina jurídica: el derecho objetivo (derecho a activar) y el

[17] No estudiamos la violación, real o posible, de la norma, ni nos avocamos en nuestro estudio a los actos de corrupción en los que incurren los actores. Por ende, nos avocamos al estudio de la activación estratégica del derecho dentro de un marco legal, mas no criminal. 
derecho subjetivo (derecho activador). Estos están inscritos en diversos textos normativos (derecho positivo). Además, se caracteriza por ser dados o reconocidos por el Estado, ser generales y abstractos, y su cumplimiento es obligatorio.

El derecho objetivo corresponde al conjunto de normas que concierne a las relaciones de los seres humanos en una determinada sociedad; mientras que el derecho subjetivo confiere a las personas derechos y libertades individuales, el derecho subjetivo lo habilita para que sean realmente ejercidos (Le Roy, Y. et Schoenenberger, M., 2011: 27-35; Roppo, V., 2015).

El marco jurídico peruano está jerárquicamente organizado, como sigue: 1) la constitución y los tratados internacionales sobre derechos fundamentales ${ }^{[18]}$, por ejemplo, la garantía de la propiedad, la figura de la concesión como derecho real y otros están reconocidos; 2) las leyes orgánicas y/o las leyes de base ${ }^{[19]}$, por ejemplo, la estructura del
MINEM y sus competencias están enmarcadas por su ley orgánica; 3) las leyes ordinarias, los decretos-ley ${ }^{[20]}$, los decretos legislativos y los demás tratados internacionales; 4) Los decretos de urgencia y decretos supremos ${ }^{[21]}$, el TUO de la LGM y sus reglamentos entran en esta categoría; 5) Las resoluciones ministeriales y viceministeriales, estas son adoptadas por los ministros de estado para que se puedan dirigir la implementación de las políticas; 6) las ordenanzas regionales y municipales, y los decretos regionales y municipales ${ }^{[22]}$, en principio los gobiernos locales no tienen competencia sobre la gran minería, pero Sí en materia de planificación del territorio y/o construcción urbana.

Los derechos reconocidos por estas normas son oponibles a terceros, sea una persona física o jurídica, privada o pública, y su reconocimiento, cumplimiento, respeto y/o disposición pueden ser demandadas ante la autoridad competente ${ }^{[23]}$, ya sea este político-administrativa o jurídica.

[18] La constitución es la norma superior del Estado, ella contiene los principios que rige la política minera tales como la concesión. En esta categoría se encuentran los tratados internacionales concernientes a los derechos fundamentales que son parte del corpus iure constitucional. Entre ellas podemos citar la convención N. ${ }^{\circ} 169$ de la OIT relativa a los pueblos indígenas y tribales.

[19] Son leyes que organizan el funcionamiento del Estado (los poderes del estado, entre otros los ministerios y las instituciones públicas constitucionalmente independientes). También, se encuentran entre ellas las llamadas leyes de desarrollo constitucional. Tales leyes son aprobadas, modificadas o derogadas por mayoría calificada (2/3) de los miembros del parlamento nacional. En consecuencia, son leyes que aseguran una estabilidad mayor en relación a leyes ordinarias.

[20] Los decretos leyes son dictadas por el ejecutivo, en regímenes dictatoriales, en la ausencia del legislativo. Los dos últimos gobiernos que dictaron este tipo de leyes fueron Juan Velasco Alvarado y Alberto Fujimori Fujimori. Los decretos legislativos son dictados por el ejecutivo por delegación del legislativo.

[21] Un decreto supremo implementa la aplicación de la ley, mediante ellas son adoptados los reglamentos de las leyes para su implementación.

[22] Estas normas son adoptadas por los gobiernos regionales y locales en el marco de sus competencias. Una vez adoptadas las normas son de obligatorio cumplimiento en su jurisdicción.

[23] En el contexto de la implementación de la política minera, el derecho objetivo es también un instrumento que permite activar instituciones, de interponer demandas civiles o denuncias penales, de apelar decisiones, de solicitar, de participar, según la naturaleza del derecho y el caso concreto. Por ejemplo, la ley de procedimiento administrativo general si se trata de un derecho o de una obligación administrativa, el código de procesal civil si se trata de un derecho o de una obligación privada, el código de procesal penal si se trata de un delito, o el código de procesal constitucional si se trata de un derecho o una obligación constitucional, y en alguna medida la normas procesales aplicables a la corte interamericana de derechos humanos o las que se aplican a la comisión interamericana de derechos del hombre. 


\section{Esquema N. ${ }^{\circ} 2$}

Programa político administrativo minero / normas para la implementación de la política minera
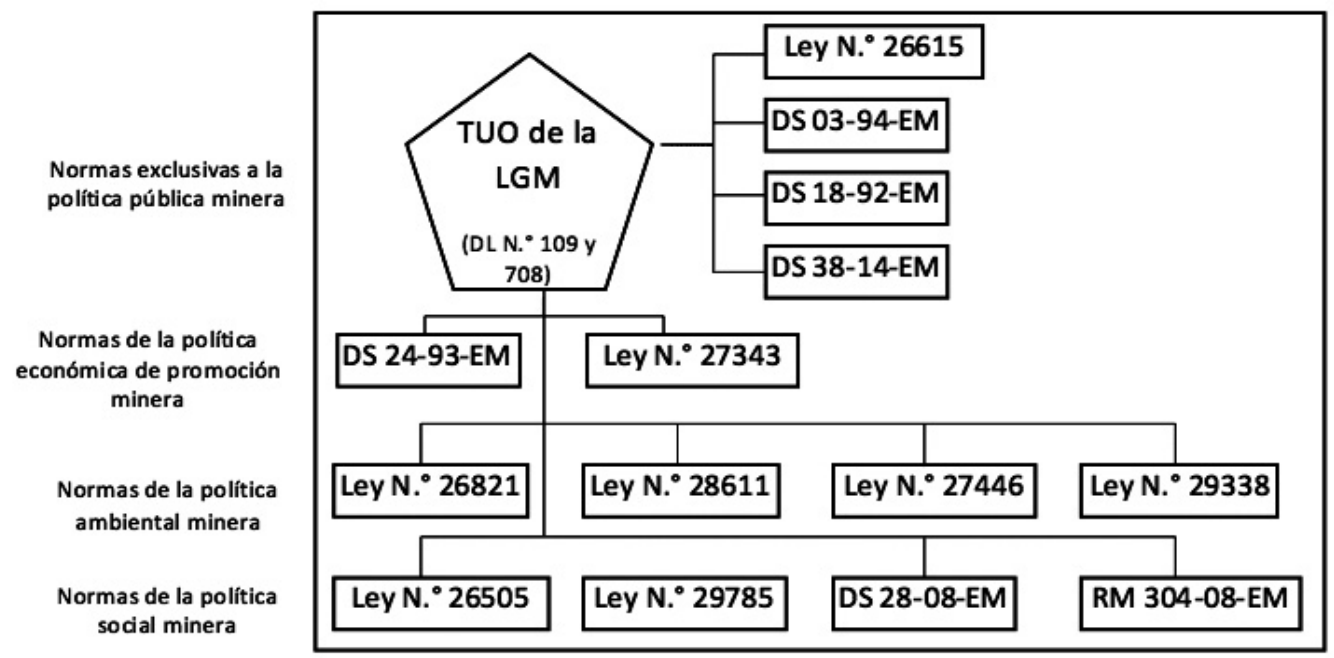

Fuente: elaboración propia.

\section{LAS ESTRATEGIAS DE ACTIVACIÓN DEL DERECHO}

La implementación de la política minera se concretiza fundamentalmente por actos administrativos $^{[24]}$. Para ello, el derecho administrativo sirve para la aplicación correcta del marco legal pertinente, sea esta nacional o internacional, bajo el principio de legalidad ${ }^{[25]}$.

Durante la implementación de la política, la norma debe ser aplicada a un caso concreto. Así, pasar de una norma abstracta y general a una decisión concreta e individual. Este proceso pone en evidencia el poder de apreciación de la norma y de su activación estratégica. Este poder corresponder al elemento micropolítico de la aplicación de la norma en la implementación de una política pública (Tanquerel, T., 2011; Moor, P. y Poltier, E., 2011).
Las estrategias de activación del derecho fueron identificadas por Remy Schweizer en varias investigaciones sobre la gestión de sistemas de irrigación en los Alpes suizos (2011 y 2014). Sus aportes nos permiten identificar el sentido en el cual las normas jurídicas son activadas y aplicadas durante la implementación de una política pública. Nosotros retomamos estos patrones con el objeto de comprender el comportamiento de los actores de la política minera.

Estos patrones muestran la capacidad de los actores para jugar con las normas, su conocimiento del régimen y su interés de influenciar el resultado final de la implementación de la política pública (el output), que es la concesión minera de beneficio.

Estas estrategias fueron organizadas en cinco patrones: pasividad, concretización, elusiva, evasiva e innovación. Estas estrategias, pueden ser ac-

[24] Las diferentes concesiones mineras y licencias mineras están otorgadas por decisiones administrativas emanadas de la autoridad político-administrativa, el INGEMMET y el MINEM.

[25] El procedimiento administrativo es muy detallado y asegurarse la aplicación de la ley, caso contrario, el acto administrativo estaría viciado de nulidad. Por ejemplo, la ley de procedimiento administrativo general, título preliminar, artículo IV, estableces los principios del procedimiento administrativo. Es imperativo que, en el juego de actores que es estratégico y racional, se tome en cuenta estos principios. 
tivadas de forma individual o en combinación con otras, según los efectos que se busca conseguir con ellas. Seguidamente, desarrollamos cada una de estas con los respectivos ejemplos identificados en estudio de casos.

\subsection{La pasividad}

La pasividad consiste en la ausencia de activación de una norma a pesar de que ella existe y está a disponibilidad. Ella puede consistir también en la inactivación de una decisión vinculante, del derecho de petición, de acción o de apelación. En estos supuestos, la pasividad del actor puede ser voluntaria, pero también existen casos donde el desconocimiento de la norma puede ser la causa de esta pasividad.

Así, el actor puede considerar que la norma no está adaptada a su caso o es ineficiente o que el statu quo es más satisfactorio y prefiere activar otras, o no activa ninguna. También, podría estar obligado a la pasividad por una insuficiente dotación de recursos de acción, como la falta de recursos económicos. De igual forma, la insuficiencia del recurso conocimiento por el que se ignora la existencia de la norma o de su contenido puede ser la causa de la pasividad.

Por ejemplo, durante la implementación del proyecto minero Cañarico, entre los años 70 hasta el 2010, la comunidad de Kañaris no interpuso ningún reclamo verbal o escrito por el uso, posiblemente irregular, de sus tierras. Los promotores mineros ${ }^{[26]}$ realizaban exploración minera y usufructo de tierras sin previa autorización de los propietarios del suelo.

Los Kañaris desconocían la existencia del proyecto y solo sabían que algún trabajo se estaba realizando, posiblemente, por el gobierno. Por el desconocimiento, no reaccionaron y dejaron pasar los hechos creyendo que eran momentáneos (Condo, V., 2017). La estrategia adoptada tanto por el MlNEM como por el promotor minero fue la de tomar ventaja de la pasividad de los Kañaris, la que fue complementada con la estrategia de evasión.

En el caso Tía María, entre el 2009 y 2011, las aprobaciones de EIA fueron suspendidas temporalmente y luego de las protestas fueron suspendidas definitivamente. El promotor no apeló la decisión, a pesar de que afirmaba que cumplía con todos los requisitos y que habían levantado todas las observaciones. Este conforme con la decisión no activó su derecho de apelación y presentó nuevo EIA y se sometió a un nuevo procedimiento.

\subsection{La concretización}

Es la activación literal de la norma o siguiendo el espíritu por la que fue adoptada. Esta estrategia no implica una aplicación homogénea ni mecánica de la norma, sino que varía de acuerdo al actor que la activa, por el nivel de precisión de la formulación de la norma (si es clara, ambigua, concisa o difusa) y/o en razón a su contenido (restrictiva, abierta o cautelar).

Un ejemplo tipo de esta estrategia es la entrega de concesiones mineras en el subsuelo por el INGEMMET $^{[27]}$. Todo el territorio nacional está dividido por ley en cuadrículas de 100 hectáreas, que a solicitud de una concesión (de 100 a 1000 hectáreas) es suficiente verificar si la parcela está entregada en concesión o protegida (INGEMMET, 2013, 2014) y luego se aplica la norma literalmente. No hay margen de maniobra porque la ley es clara, concisa y restrictiva. Por ende, los promotores adquieren muchas concesiones en aplicación literal de la norma.

Otro ejemplo de esta estrategia la encontramos en el proyecto Cañariaco. En el periodo 2004 a 2005, el promotor minero publica el EIA en dos diarios, uno de tiraje nacional y otra en Chiclayo, en idioma español. El promotor cumplió estrictamente con lo estipulado en la norma, porque le era muy ventajoso. Estos diarios son de distribución urbana;

[26] El proyecto minero Cañariaco se privatiza en el año 2000, previa a esta el proyecto era propiedad del Estado peruano.

[27] Aclaramos que el Instituto Geológico Minero y Metalúrgico (INGEMMET) es la autoridad competente para la entrega de concesiones mineras y es un organismo autónomo adscrito al MINEM. 
sin embargo, los Kañaris viven en área rural muy alejada de Chiclayo ${ }^{[28]}$ donde difícilmente, si no imposible, se comercializan diarios. Además, La gran mayoría solo habla quechua, una minoría es bilingüe, generalmente, sus autoridades. Para el promotor, un actor que busca evitar conflictos, concretizar literalmente la norma le facilitó obtener una licencia minera.

Con esta misma estrategia los Kañaris utilizaron su idioma para evadir denuncias penales. Después de protestas contra el proyecto, sus dirigentes fueron denunciados penalmente y cuando estos rindieron sus testimonios lo hicieron en quechua. Los Kañaris sabían que tienen el derecho a expresarse en su idioma y a tener un traductor, pero también sabían que las autoridades no conocían el idioma y no contaban con traductores. Así, activando literalmente la norma, lograron que las investigaciones adolezcan de garantías y se quiebre (Condo, V., 2017).

\subsection{La elusion}

La elusión ${ }^{[29]}$ como estrategia es la activación de la norma para fines para las cuales no fue prevista. Ella consiste en jugar con los límites de la norma, a eludir su contenido y a usarla para fines convenientes del actor, pero sin jamás llegar a transgredirla. Esta estrategia se apoya en la existencia de lagunas, dicotomías o incoherencias normativas. Aclaramos que el uso excesivo y sistemático de esta estrategia podría constituir abuso del derecho.
Un ejemplo de esta estrategia la encontramos en los casos Tía María y Cañaris. Las normas de participación de ciudadanos para los talleres de información y participación, en la implementación de un proyecto minero, no define el número de participantes ni determina cómo se acredita esta participación. Hemos encontrado que muchos de estos talleres se desarrollaron con participación de algunas decenas de personas, en locales muy pequeños o con controles de ingreso muy selectivos (Condo, V., 2017). La norma tiene como fin informar a la población en general, pero tiene lagunas y es ambigua y en base a estas se busca eludirla.

Otro ejemplo de esta estrategia encontramos en el caso Tía María. Esta vez, la Municipalidad de Coca Chacra, haciendo uso de su competencia en materia de prevención de riesgos en espectáculos públicos, denegó sistemáticamente por más de un año el uso de locales para la realización de los talleres bajo el argumento de que no cumplen con los estándares $^{[30]}$ (Condo, V., 2017). Ciertamente, esta competencia le fue otorgada para velar por la seguridad, mas no para bloquear la implementación de la política pública minera.

\subsection{La evasión}

Por esta estrategia ${ }^{[31]}$ el actor se resiste a la aplicación de la norma, de manera más o menos frontal y abierta. Schweizer distingue que esta estrategia comprende dos procedimientos distintos: evasión en uso de las normas y la evasión por confrontación.

[28] Para hacer mi trabajo de campo, tuve que viajar desde Chiclayo más de 8 horas en distintos transportes para llegar a la comunidad y para regresar tuve que esperar más de medio día a pie de carretera y ver si pasaba un camión que pudiera llevarme hasta Pucara, la ciudad más cercana y, de ahí, tomar un bus de regreso a Chiclayo.

[29] Schweizer denomina esta estrategia détournement, palabra francesa que traducida literalmente al español significa 'desvió'. Nosotros para que sea mejor entendida en español la denominamos elusión, porque se adapta este término mejor a la idea que se quiere expresar.

[30] El único local que cumplía con los requisitos exigidos para la realización de eventos públicos le pertenecía a la Municipalidad de Coca chacra. El uso de este local también se le rechazaba sistemáticamente al promotor.

[31] Para la denominación de esta estrategia, Schweizer usa el termino francés contournement que traducida literalmente significa 'dar la vuelta o circunvalar', nosotros adoptamos el término evasión para mejor adaptarla al idioma. 
El primero consiste en la resistencia de la aplicación de la norma, para ello, se vale de la aplicación de otra norma, esta última es contraria al espíritu de la norma «supuestamente» aplicable. Implica, necesariamente, la existencia de dos o más normas con espíritus, más o menos contrarios, más o menos alternativos. Ello implica también la evasión de obstáculos normativos a través del aligeramiento del procedimiento o por una negociación de las condiciones de su aplicación.

El segundo consiste en que el actor transgrede la norma, sin que llegue necesariamente al ámbito de la criminalidad o la ilegalidad. Esta estrategia se sustenta en el conocimiento profundo de las estructuras de la norma e implica fineza en su diseño e implementación. Esta situación se presenta en un contexto donde la práctica es extendida y repetitiva. Estas estrategias, como lo indicamos anteriormente, están en el límite de la ilegalidad y que podrían ser sancionados mediante procedimientos escrupulosos.

El primer subtipo de esta estrategia es frecuentemente utilizado durante la implementación de proyectos mineros. Es frecuente que los actores apelen sistemáticamente las decisiones del MINEM. Se denuncien mutuamente por poner en peligro, aparente o real, la salud, el medio ambiente, la calidad del agua, la seguridad, el tránsito, la propiedad, etc. Con esto se busca ganar tiempo y/o neutralizar al rival, momentáneamente, pero no necesariamente ganar los procesos.

Un ejemplo del segundo subtipo lo encontramos en el otorgamiento de licencias mineras sobre propiedad de los Kañaris. Este pueblo indígena no tiene bien delimitados sus territorios y son tan extensos que son inhabitados. También, se aprovechó que sus autoridades no estén formalmente registradas o reconocidas por el Estado. En este contexto, el MIEM otorga licencias mineras con acceso y uso del terreno (servidumbres) sin el consentimiento del propietario, declarándolas terrenos eriazos o bajo un aparente consentimiento.

\subsection{La innovación}

Esta estrategia nos renvía a la creación de soluciones ad hoc, innovadoras, dentro del margen de normas generales y abstractas. Con esta estrategia se busca ampliar la aplicación de una norma para supuestos que no estaban previstos en ella, en suma, se busca ir más allá de la norma. Esta estrategia es raramente activada por los actores; no obstante, en nuestro estudio de casos hemos encontrado ejemplos muy interesantes, de los cuales citaremos dos.

Bajo esta estrategia, en los casos de Tintaya, Antapacay y Cañaris encontramos que se modificaron el régimen de derecho de las propiedades y la situaron en otros distintos. Tomando en cuenta el orden de mayor y menor protección de la propiedad del suelo (ver la sección respecto al comportamiento selectivo), es favorable para un proyecto minero que el suelo se encuentre en régimen privado o público, que en el de comunidades campesinas o indígena.

Así, para el proyecto Antapacay y parte de Tintaya, el MINEM y los promotores mineros buscan un régimen favorable a los proyectos mineros. Así, incitaron ${ }^{[32]}$ a los propietarios mediante acuerdos de colaboración, a que pasen del régimen de propiedad indígena, a la propiedad comunal y, finalmente, al régimen privado e individual ${ }^{[33]}$. Así, la comunidad indígena de Antaycama se disuelve y se forman varias comunidades campesinas. Los habitantes de las tierras que interesaban a los proyectos mineros adoptaron el régimen privado de propiedad o luego de ser comunidad adoptaron posteriormente este régimen y luego las vendieron a los promotores mineros (Condo, V., 2017).

[32] El incentivo se ha realizado tomando en cuenta el contexto interno y previo que existía en el pueblo indígena previo a los proyectos mineros. Los incentivos a veces fueron directos, soporte técnico y económico para disolución de la comunidad, en otras se aprovechó el contexto, disputas internas, y en otras los antecedentes, como la ya existencia del proyecto Tintaya sobre terrenos expropiados.

[33] El régimen privado es la propiedad que se rige por las normas del código civil, la llamamos así para distinguirla del régimen privado donde la propiedad pertenezca a un colectivo. 
Esta misma estrategia es activada en el caso Cañaris, pero esta vez por los propietarios del suelo en busca de un régimen desfavorable al proyecto minero. La, entonces, comunidad campesina de Kañaris solicitó al Ministerio de Cultura y al MINEM su reconocimiento como pueblo indígena, en base a títulos de propiedad coloniales y republicanos. Así, su régimen de propiedad podía pasar al de régimen de protección de pueblos indígenas. Este régimen exige mayores condiciones para la implementación de proyectos mineros, por ejemplo, la consulta previa. Hasta la fecha, la implementación de esta estrategia sigue en curso y ya ha llegado a instancias internacionales como la Comisión y la Corte Interamericana de Derecho Humanos.

Además, los Kañaris, bajo esta estrategia, exigían que se les haga una consulta previa. Sin embargo, ella fue sistemáticamente denegada por el MINEM por que niegan que sean un pueblo indígena. Los Kañaris, frente a eso, realizan una autoconsulta sin precedentes para que sus miembros se pronuncien sobre la aceptación o rechazo a la actividad minera en su territorio ${ }^{[34]}$. Es innovadora porque la consulta no está prevista para autoconsultarse, pero se busca con ella los mismos efectos que la consulta previa.

La innovación como estrategia ha resultado muy fructífera para los actores que la activan. Sin embargo, como ya lo mencionamos, no es frecuente que se activen. Ella implica mucha inversión en recursos, no solo para su diseño, sino también para su implementación.

De esta forma, las estrategias de activación conciernen las normas del derecho y siguen patrones para su activación. Hemos presentado las estrategias y algunos ejemplos; sin embargo, el juego de actores es más complejo y más intenso, desarrollamos este con mayor detalle en nuestro trabajo de investigación. Para terminar con esta parte, es necesario remarcar que el objetivo buscado por los actores, la legitimación, no se alcanza con la sola activación estratégica del recurso derecho, sino que busca influenciar la construcción de un acuerdo regulativo local, la entrega o no de una concesión minera para su explotación o no efectiva (el output de la política minera) bajo ciertas condiciones ${ }^{[35]}$.

\section{CONCLUSIONES}

El estudio de la activación estratégica del derecho como parte del juego de actores ha obtenido consigo muchos aportes para la teoría y el análisis de las políticas públicas. Los investigadores y creadores del Institutional Resources Regime (IRR) a la fecha siguen profundizando los estudios respecto a esta. Por ejemplo, Peter Knoepfel, en su última publicación Les ressources d'action publique, vers une nouvelle lectura du pouvoir (2017), estudia detalladamente cada uno de los recursos de acción pública y hace especial mención al derecho como recurso.

Desde nuestras investigaciones, también, hemos aportado a la validación del marco de análisis del IRR, sobre todo en lo que concierne a las estrategias para la implementación de políticas públicas mineras, con un énfasis particular en la activación estratégica del derecho de propiedad, derechos de uso y derechos de participación.

A modo de conclusión, abordaremos dos usos que se pueden dar a este marco de análisis. Un trabajo de investigación, de una u otra forma, tiene que tener utilidad, si no es para una gran parte de la sociedad, al menos para un grupo considerable de ella. Entonces, la primera utilidad que se le puede dar a este trabajo es estrictamente teórico, para el mundo académico y, el segundo, práctico, para el mundo laboral.

Este trabajo analiza, sistematiza e identifica patrones de diferentes estratégicas de activación del derecho que los actores despliegan a lo largo de

[34] Esta consulta, más que enmarcarse en las normas de la consulta previa se adaptaría a los procedimientos internos de la comunidad para la toma de decisión. Existen precedentes, bajo esta lógica de autoconsultarse, llamados consulta ciudadana o popular, para aceptar o rechazar el proyecto minero Tambogrande y Tía María.

[35] El tema sobre la constitución Acuerdo Regulativo Local (ARL) no se aborda en este trabajo, pero fue uno de los principales objetos de estudio de nuestra investigación doctoral. 
la implementación de la política minera. Ello puede servir de marco teórico para el análisis y evaluación de la implementación de políticas públicas en general, así como para el estudio del derecho. Los investigadores sociales pueden aplicar estos patrones para estudiar el fenómeno del juego de actores desde una visión del derecho, así como los juristas pueden estudiar el derecho desde fuera del mundo legalista, que es extremadamente jerarquizado y cerrado. Entonces, este trabajo tiene una utilidad teórica para futuros estudios e investigaciones.

No solo los académicos pueden servirse de este marco de análisis, sino también los que se encuentran en el mundo de la práctica, entonces, tiene una utilidad práctica. Este análisis puede servir a las autoridades que dirigen la implementación de políticas públicas, para analizar y evaluarlas, no sirve únicamente para las políticas mineras sino cualquier otra política. También, es útil para los promotores mineros o para cualquier otro promotor de proyectos, para diseñar estrategias de implementación, anticipar los eventos, reforzar sus actuales estrategias o reformularlas. También, puede servir para otros actores, propietarios, detentores de derechos de uso, las ONG y otras organizaciones para velar por sus intereses y/o valores, así evitar el uso exclusivo, la violencia y usar mejor los recursos de acción pública que pueden ser más efectivos.

\section{BIBLIOGRAFÍA}

Aguado M. (2009). La concesión minera. Jurisdicción y procedimiento. Revista de Derecho Administrativo PUCP, N. ${ }^{\circ}$ 8. Lima, Perú: Editorial PUCP.

Baca E. (2013). Estudio sobre marco normativo minero en Perú. Lima, Perú: Editorial Propuesta Ciudadana.

Benavides R. (2012). La minería responsable y sus aportes al desarrollo del Péru. Lima, Perú: Editorial Comunica2 SAC.

Bebbington A., Bury J. (2009). Institutional challenges for mining and sustainability in Peru. Vol. 106. N. ${ }^{\circ} 41$. Washington, Estados Unidos: Ed. PNAS.
Castro X. (2009). El Título Minero como Acto Administrativo Habilitante». Revista de derecho administrativo PUCP, N. ${ }^{\circ}$ 8. Lima, Perú: Editorial PUCP.

Condo V. (2017). Politiques publiques minières: stratégies pour la mise en œuvre de grands projets miniers, entre le succès et l'échec. Quatre études de cas de mise en œuvre des grands projets miniers au Pérou (Tesis doctoral). Lausanne, Suiza: Ed. UNIL.

De Buren G. (2012). La régulation des interdépendances entre les forêts et l'eau potable en Suisse. Lausanne, Suiza: Ed. IDHEAP.

(2013). La régulation des interdépendances entre les forêts et l'eau domestique en Indonésie. Lausanne, Suiza: Ed. IDHEAP.

(2014). La gestion des services environnementaux: entre règles et régulation négociée (Tesis doctoral). Lausanne, Suiza: Ed. UNIL.

Knoepfel P.; Corinne L.; Fréderic V. (2006). Analyse et pilotage des politiques publiques. Zurich/ Chur, Suiza: Verlag Ruegger.

(2011). Public policy analysis. Great Britain: Bristol University's press.

Knoepfel P. (2007). Environnemental Policy analysis. Berlin: Springer.

(2017). Les ressources d'action publique - vers une nouvelle lecture du pouvoir. Zurich/Genève, Suiza: Seismo.

Knoepfel P. Nahrath St., Savaray J., Varone F. (2010). Analyse des politiques suisses de l'environnement. Zurich/Chur, Suiza: Editions Ruegger.

Le Roy Y. et Schönenberger M. (2011). Introduction générale au droit Suisse. 3eme édit. Genève-Zurich, Bale, Suiza: Ed. Schulthess Éditions Romandes SA.

ONDS. (2013). Conflictos sociales y gestión pública. Willaqniki, N. ${ }^{\circ}$ 07. PCM \& ONDS. Lima, Perú. 
(2013). Informe de diferencias, controversias y conflictos sociales. Willaqniki, N. ${ }^{\circ}$ 18. PCM \& ONDS. Lima, Perú.

(2013). Mesas de dialogo, mesas de desarrollo y conflictos sociales en el Perú. Willaqniki, N. ${ }^{\circ}$ 05. PCM \& ONDS. Lima, Perú.

Defensoría del Pueblo. (2007). Los conflictos socioambientales por actividades extractivas en el Peru $\square$. Reporte DP. Lima, Perú: Ed. Defensoría del Pueblo.

(2012). Violencia en los conflictos sociales: Informe Defensorial N ${ }^{\circ} 156$. Lima, Perú: Ed. Defensoría del Pueblo.

IIMP-MINEM. (2010). Minería peruana: contribución al desarrollo económico y social. Reporte IIMP-MINEM. Lima, Perú: Ed. IIMP.

Ministerio de Energía y Minas. (2014). Anuario Minero 2014. Reporte MINEM. Lima, Perú.
(2015). Anuario Minero 2015. Perú.

Instituto Geológico Minero y Metalúrgico. (2013). Perú: Atlas Catastral Minero y Geológico. Reporte INGEMMET. Lima, Perú: Ed. INGEMMET.

(2014). Perú: Atlas Catastral Minero y Geológico. Lima, Perú: Ed. INGEMMET.

Schweizer R. (2011). Apport du concept d'arrangement régulatif à l'analyse de la gestion des systèmes d'irrigation sous l'angle de la durabilité. Working paper de l'IDHEAP, N. ${ }^{\circ} 8$. Lausanne, Suiza.

(2014). Stratégies d'activation $d u$ droit dans les politiques environnementalesCas autour des bisses valaisans (Tesis doctoral). Lausanne, Suiza: Ed. UNIL.

Tanquerel T. (2011). Manuel de droit administratif. Zurich, Suiza: Ed. Schulthess Verlag. 